\title{
Combined Hormonal Contraceptive Usage in Women With COVID-19
}

\author{
Zehra Kurdoğlü ${ }^{1 *(1)}$
}

$\longrightarrow$ OVID-19 caused by SARS-CoV-2 virus is a disease affecting all the world as a pandemic. This new coronavirus causes various health problems like pneumonia, acute respiratory distress syndrome (ARDS), myocardial dysfunction, kidney injury, gastrointestinal diseases, and ocular symptoms $(1,2)$. It also causes a systemic inflammatory response and activates the coagulation cascade in affected patients after binding to angiotensin-converting enzyme 2 (ACE-2) receptors on endothelial cells (3).

Combined hormonal contraceptives (CHCs) containing varying doses of estrogens and progesterone have a potential risk of increasing thrombosis (4). The relative risk of venous thromboembolism (VTE) in combined oral contraceptive (COC) users is three-to-five-fold (5). Some studies revealed that the risk of thrombosis is lower with second-generation oral contraceptives using norgestrel or levonorgestrel than the third-generation ones using desogestrel and gestodene as a progestin (6). The risk of VTE might be higher in unclassified oral contraceptives containing drospirenone and cyproterone acetate (7). However, the unwanted pregnancies occurring when such contraceptives are discontinued are associated with a much higher risk of VTE (4.29-fold compared to the non-pregnant women) (8). Therefore, the family planning counseling for CHC usage in the patients with COVID-19 should be able to give a satisfactory answer to the question whether it is safe or not.

Various Spanish scientific societies evaluated this hot topic to guide the women with COVID-19 using CHC. According to their recommendations, in the patients with COVID-19 admitted to the hospital, CHC should be discontinued and a low molecular weight heparin (LMWH) be initiated at the prophylactic dose. If the patient's condition is not serious and $\mathrm{CHC}$ is used for reasons other than contraception, a switch to progestogen-only contraceptives (POCs) and adding a prophylactic LMWH is logical. In severe cases or ones treated in the intensive care unit, the dosage of LMWH

\begin{abstract}
Prof. Zehra Kurdoğlu worked as an Assistant Professor between 2009 and 2012, and as an Associate Professor between 2012-2014 in the Department of Obstetrics and Gynecology, Faculty of Medicine, Van Yuzuncu Yil University. Between the years of 2014-2018, she worked in the Department of Obstetrics and Gynecology of Ankara Training and Research Hospital. She was trained on robotic surgery at the Division of Minimally Invasive Gynecology and Research in the Department of Obstetrics and Gynecology of the University of

Texas Medical Branch at Galveston, Texas, USA. She started to work at Yildirim Beyazıt University Faculty of Medicine, Department of Obstetrics and Gynecology in 2018. At national and international level, she has published 100 scientific papers, has written 2 book chapters, and has received over 800 citations for her articles. She was a member of the editorial board of Van Medical Journal, Turkish Journal of Obstetrics and Gynecology, Turkiye Klinikleri Gynecology Obstetrics, Eastern Journal of Medicine, previously. She is a member of the editorial board of International Journal of Women's and Reproduction Sciences and Crescent Journal of Medical and Biological Sciences.
\end{abstract}

should be increased according to the hospital protocol. In the women with mild COVID-19 symptoms and treated at home, CHC may be continued or switched to a POC or a non-hormonal contraceptive method. CHC should be withdrawn and a prophylactic LMWH be added in the patients with pneumonia or persistent respiratory symptoms and treated at home. If a contraceptive method is required for these women, POCs or nonhormonal contraceptive methods may be used together with a prophylactic LMWH. If the mildly symptomatic women with unconfirmed COVID-19 diagnoses require hormonal contraception, CHC may be continued or POCs can be used instead. If the patient has persistent respiratory symptoms and treated at home, $\mathrm{CHC}$ should be withdrawn and a prophylactic LMWH is initiated. If a hormonal contraception is essential for these patients, POCs or non-hormonal contraceptive methods may be advised with prophylactic LMWH (9).

As a conclusion, continuing to use combined hormonal contraceptives or switching to an alternative contraceptive method and adding an LMWH should be tailored to disease severity in the women with COVID-19 avoiding unplanned pregnancies.

Received 28 December 2020, Accepted 2 January 2021, Available online 3 January 2021

${ }^{1}$ Department of Obstetrics and Gynecology, Ankara Yildirim Beyazıt University Faculty of Medicine, Ankara, Turkey.

*Corresponding Author: Zehra Kurdoğlu, Tel: +90 3125526000; Email: zkurdoglu@ybu.edu.tr 


\section{Ethical Issues}

Not applicable.

\section{Conflict of Interests}

The author has no conflicts of interest to disclose.

\section{References}

1. Gupta A, Madhavan MV, Sehgal K, et al. Extrapulmonary manifestations of COVID-19. Nat Med. 2020;26(7):10171032. doi: 10.1038/s41591-020-0968-3

2. Nader D.N, Mahmoodpoor A. COVID-Associated Respiratory Distress Syndrome (CARDS) in Pregnancy; What Makes it so Different? Int J Womens Health Reprod Sci. 2020;8(4):336337. doi:10.15296/ijwhr.2020.54

3. Franchini M, Marano G, Cruciani M, et al. COVID-19associated coagulopathy. Diagnosis (Berl). 2020;7(4):357363. doi: 10.1515/dx-2020-0078

4. Vinogradova Y, Coupland C, Hippisley-Cox J. Use of hormone replacement therapy and risk of venous thromboembolism: nested case-control studies using the QResearch and CPRD databases. BMJ. 2019;364:k4810. doi: 10.1136/bmj.k4810. Erratum in: BMJ. 2019;364:1162

5. van Vlijmen EF, Veeger NJ, Middeldorp S, et al. Thrombotic risk during oral contraceptive use and pregnancy in women with factor $\mathrm{V}$ Leiden or prothrombin mutation: a rational approach to contraception. Blood. 2011;118(8):2055. doi: 10.1182/blood-2011-03-345678

6. Hennessy S, Berlin JA, Kinman JL, Margolis DJ, Marcus SM, Strom BL. Risk of venous thromboembolism from oral contraceptives containing gestodene and desogestrel versus levonorgestrel: a meta-analysis and formal sensitivity analysis. Contraception. 2001;64(2):125. doi: 10.1016/s00107824(01)00234-7

7. Gronich N, Lavi I, Rennert G. Higher risk of venous thrombosis associated with drospirenone-containing oral contraceptives: a population-based cohort study. CMAJ. 2011;183(18):E1319. doi: 10.1503/cmaj.110463

8. Heit JA, Kobbervig $\mathrm{CE}$, James $\mathrm{AH}$, et al. Trends in the incidence of venous thromboembolism during pregnancy or postpartum: a 30-year population-based study. Ann Intern Med 2005; 143:697. doi: 10.7326/0003-4819-143-10-20051115000006

9. Ramírez I, De la Viuda E, Baquedano L, et al. Managing thromboembolic risk with menopausal hormone therapy and hormonal contraception in the COVID-19 pandemic: Recommendations from the Spanish Menopause Society, Sociedad Española de Ginecología y Obstetricia and Sociedad Española de Trombosis y Hemostasia. Maturitas. 2020;137:5762. doi: 10.1016/j.maturitas.2020.04.019

(C) 2021 The Author(s); This is an open-access article distributed under the terms of the Creative Commons Attribution License (http:// creativecommons.org/licenses/by/4.0), which permits unrestricted use, distribution, and reproduction in any medium, provided the original work is properly cited. 